\title{
Pioneiros e fazendeiros de São Paulo: a história ambiental e a obra de Pierre Monbeig
}

Pioneers and farmers from São Paulo: the environmental history and

Pierre Monbeig's work

\author{
Marcelo Lapuente Mahl \\ Universidade Federal de Uberlândia. Uberlândia, Minas Gerais, Brasil
}

\begin{abstract}
Resumo: O geógrafo francês Pierre Monbeig integrou o grupo que, no início da década de 1930, chegou ao Brasil para compor um dos primeiros núcleos de docentes da Universidade de São Paulo. Este artigo apresenta uma reflexão sobre a sua obra "Pioneiros e fazendeiros de São Paulo" (1984b), à luz da história ambiental, compreendendo a importância da pesquisa de Monbeig para os estudos dedicados às relações entre o homem e o meio ambiente no contexto da expansão econômica paulista, nas primeiras décadas do século XX. Mesmo após a sua volta à França, em meados da década de 1940, Pierre Monbeig continuou em contato com seus alunos e orientandos no Brasil, produzindo obras fundamentais sobre o país que nunca saiu de seu horizonte intelectual.
\end{abstract}

Palavras-chave: Pierre Monbeig. História ambiental. Fontes históricas.

\begin{abstract}
The French geographer Pierre Monbeig arrived in Brazil with other researchers in the early nineteen-thirties to join one of the first groups of professors at the University of São Paulo (USP). This paper presents a reflection upon his work, "Pioneers and Farmers from São Paulo" (1984b) ("Pioneiros e fazendeiros de São Paulo"), from the perspective of environmental history. The objective is to understand the importance of Monbeig's research to studies that focus on the relationship between humans and the environment within a scenario of economic expansion in São Paulo in the first decades of the twentieth century. Even after returning to France in the mid-forties, Pierre Monbeig maintained contact with his students and advisees in Brazil, producing fundamental work about the country that never left his intellectual horizon.
\end{abstract}

Keywords: Pierre Monbeig. Environmental history. Historical sources.

MAHL, Marcelo Lapuente. Pioneiros e fazendeiros de São Paulo: a história ambiental e a obra de Pierre Monbeig. Boletim do Museu Paraense Emílio Goeldi. Ciências Humanas, v. 13, n. 1, p. 147-158, jan.-abr. 2018. DOI: http://dx.doi.org/10.1590/1981.81222018000100008. Autor para correspondência: Marcelo Lapuente Mahl. Universidade Federal de Uberlândia. Faculdade de História. Av. João Naves, 2121. Uberlândia, MG, Brasil. CEP 38408-100 (mlmhistor@hotmail.com).ORCID: https://orcid.org/0000-0001-6749-7654.

Recebido em 08/06/2017

Aprovado em 19/09/2017 


\section{PIERRE MONBEIG E SUA TRAJETÓRIA INTELECTUAL NO BRASIL}

Muitos dos pesquisadores da chamada 'missão francesa' que formaram o núcleo docente inicial da Faculdade de Filosofia, Ciências e Letras de São Paulo, a partir de 1934, lembravam-se dessa experiência profissional como um momento marcante de suas trajetórias intelectuais, estabelecendo, desde então, vínculos afetivos e profissionais duradouros com o país. Três, em especial, salientaram a importância de suas atividades no Brasil em momentos distintos de suas longevas carreiras: Pierre Monbeig, Claude Lévi Strauss e Fernand Braudel'1. À época, jovens oriundos da universidade francesa, enfrentaram, a seu modo, os desafios de iniciar uma atividade profissional em terras estrangeiras, em meio às incertezas próprias de um ambiente institucional acadêmico ainda em construção.

$\mathrm{Na}$ trajetória intelectual de Pierre Monbeig, particularmente, o Brasil foi tema sempre presente. Aqui atuou como professor e pesquisador durante onze anos, mais precisamente entre 1935 e 1946, ajudando a consolidar os pressupostos propagados na virada do século XIX por Vidal de La Blache, entre alunos como Aziz Ab'Sáber e Pasquale Petrone, que mais tarde acabaram, eles próprios, tornando-se referências no campo da geografia nacional².

Este vínculo profícuo com o país que lhe deu oportunidade, segundo o próprio Monbeig, de se aventurar quando jovem em uma verdadeira 'viagem de exploração', pode ser verificado em seus livros e artigos, cujos temas principais foram o Brasil e os problemas brasileiros, como "Ensaios de geografia humana brasileira" (Monbeig, 1940), "Brasil" (Monbeig, 1969), "Pioneiros e fazendeiros de São Paulo" (Monbeig, 1984b) e "O crescimento da cidade de São Paulo" (Monbeig, 2004), além de textos publicados na imprensa, principalmente no jornal "O Estado de São Paulo"3. Ao mesmo tempo, Monbeig ajudou na consolidação da Associação dos Geógrafos Brasileiros (AGB), ao lado de Caio Prado Júnior e Pierre Deffontaines, sendo um colaborador contumaz das publicações desta organização4.

A situação dos estudos geográficos no Brasil, no período em que Monbeig chegou ao país, limitava-se, segundo ele próprio - recordando-se das palavras do amigo Delgado de Carvalho -, "[...] a ensinar os alunos a decorarem a lista telefônica [...]” (Mota, 1981, p. 254). Por outro lado, a primeira metade do século $X X$ foi marcada por modificações teórico-metodológicas no pensamento geográfico, quando os pesquisadores, segundo as palavras de Moraes (1983, p. 94), buscaram "[...] caminhos metodológicos até então não trilhados [...]”, estimulados principalmente por leituras interdisciplinares, em um momento muito similar de questionamentos e de rupturas que envolveram também os historiadores reunidos ao redor dos Annales, como Marc Bloch e Lucien Febvre ${ }^{5}$. Como afirma Salgueiro (2006, p. 19), a geografia dos herdeiros de Vidal de La Blache afirma-se como "[...] uma ciência das coisas vistas no terreno, fundada na dimensão visual, temporal e humana [...]". Essa concepção de um saber vivo,

1 Exemplos dos autores citados a respeito dessas lembranças sobre o Brasil podem ser encontrados em: Mota (1981), Braudel (1984), Lévi-Strauss (2011) e Lévi-Strauss e Eribon (2005).

2 Além de Pierre Monbeig, Pierre Deffontaines e Francis Ruellan também contribuíram para a forte marca francesa na formação dos nossos primeiros geógrafos acadêmicos. Sobre essa questão, ver Moreira (2008).

3 Citamos aqui somente os livros mais conhecidos, editados no Brasil. Além disso, muitas das informações aqui apresentadas sobre a trajetória de Pierre Monbeig, como suas impressões sobre o país e o ambiente cultural e intelectual observado durante o período em que atuou como professor na Universidade de São Paulo, são tributárias de dois textos bastante citados pelos que se dedicam ao estudo da obra do geógrafo francês. O primeiro é a transcrição da entrevista direcionada por Lourenço Dantas Mota e Antonio Carlos Pereira para o jornal "O Estado de São Paulo"; o segundo é um relato bastante emocional, repleto de recordações, mas não menos rigoroso do ponto de vista analítico, escrito por Ab'Sáber (1994) e publicado na revista "Estudos Avançados".

4 Sobre os primeiros anos da AGB, ver lumatti et al. (2008).

5 Pierre Monbeig foi muito próximo de Lucien Febvre e de Fernand Braudel, nomes que marcaram a historiografia francesa. Em verdade, tanto Febvre quanto Braudel atuaram em conjunto, em meio a disputas acirradas no campo intelectual francês, em defesa da escrita da história propagada pelos pesquisadores reunidos ao redor dos Annales. Sobre essas disputas, ver Delacroix et al. (2012). 
atento às transformações, tanto do mundo natural quanto das sociedades, confrontava-se com a geografia em grande parte descritiva do século XIX. Portanto, o que se buscava na primeira metade do século $X X$ era uma geografia do movimento, aludindo às interações entre o homem e a natureza ao longo do tempo. Além disso, valorizava-se o trabalho de campo e as observações in loco, com o pesquisador imerso no espaço, o qual buscava compreender.

Essa postura crítica e ativa perante o objeto de pesquisa será especialmente incorporada à prática de Monbeig, que, durante os anos que passou no Brasil, viajou pelos chamados 'sertões' paulistas, muitas vezes em companhia de seus alunos, característica que marcava os seus cursos na Universidade de São Paulo. Como afirma Ab'Sáber (1994), o trabalho de campo era fundamental nos estudos conduzidos pelo mestre francês:

[...] Nada mais importante poderia ter marcado nosso destino, na escolha de uma ciência para ser cultivada pelo resto de nossas vidas, do que aquela primeira e predestinada excursão sobre o terreno. A iniciativa era da inteira responsabilidade de Monbeig. O itinerário escolhido envolvia a saída a partir das colinas de São Paulo e um transecto pelas serranias de Jundiaí, até atingir setores da chamada depressão periférica paulista. De São Paulo a Jundiaí e a Campinas, até Salto e Itu, com regresso pelo famoso canyon do Tiête, passando por Cabreuva, Pirapora do Bom Jesus, Sant'ana do Parnaíba e subúrbios ocidentais de São Paulo. Encantou-nos, sobretudo, a dinâmica dos caminhamentos e a acuidade das observações do mestre Pierre Monbeig [...] (Ab'Sáber, 1994, p. 225 , grifo do autor).

A observação minuciosa da paisagem e dos fenômenos sociais constitui, dessa forma, uma das bases das ideias propagadas por Vidal de La Blache, estando incorporada à prática de Monbeig ${ }^{6}$. Esse olhar renovado sobre a geografia pôde ser desenvolvido de forma fértil após a sua chegada ao
Brasil, momento de atuação profissional que coincidiu com o processo de expansão econômica paulista rumo ao interior de São Paulo, que se encontrava em pleno vigor? ${ }^{7}$. Foi um período de extrema circulação de capitais, pessoas e produtos, aspectos que prenderam a atenção do jovem professor. Logo, abandonou o seu plano inicial de pesquisa, idealizado ainda durante o seu período de graduação, de efetuar um estudo sobre as ilhas Baleares, na Espanha, para se debruçar sobre as profundas transformações em curso no estado.

A partir da formulação desse novo problema, seguiu-se uma longa pesquisa, a qual, posteriormente, deu origem ao seu doutorado, defendido na Sorbonne, em 1949, tendo sido indicado ao prêmio de melhor tese pela Fundação Nacional de Ciências Políticas, já no ano seguinte. O trabalho foi publicado em 1952, na França, pela Editora Armand Colin, e teve a sua primeira versão brasileira, e até agora única, publicada em 1984, pela editora Hucitec-Polis, com tradução de Ary França e de Raul de Andrade e Silva, sob o título "Pioneiros e fazendeiros de São Paulo" (1984b). Nesta obra, resultado de um abrangente e longo trabalho de campo, além de um sem número de entrevistas, pesquisas em arquivos públicos e privados, Monbeig utiliza as expressões franja pioneira (frange pionnière) e marcha pioneira (marche pionnière), para designar tanto os espaços quanto as movimentações populacionais e de capitais pelo interior paulista, nas primeiras décadas do século $X X$, impulsionadas pela ampliação do complexo cafeeiro ${ }^{8}$. Efetivamente, a obra apresentou-se como um desafio monumental, ao abarcar dezenas de cidades e populações do interior paulista, analisadas por meio de tabelas, dados econômicos, relatórios oficiais de secretarias e ministérios, estudos cartográficos, além de entrevistas, realizadas pelo próprio autor, que visitou grande parte das regiões abordadas (Figuras 1 e 2).

6 Sobre a formação acadêmica de Pierre Monbeig, ver Andrade (2011).

7 Além de Vidal de La Blache, os trabalhos de Elisée Reclus, Jean Brunhes e Max Sorre também marcaram a história do pensamento geográfico na primeira metade do século XX. Sobre esses autores, ver Moreira (2008).

8 Sobre as interpretações das franjas pioneiras disponíveis nas primeiras décadas do século $X X$ e as reflexões de Monbeig acerca desta questão, ver Nogueira (2013).

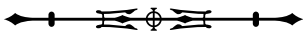


PIERRE MONBEIG

\section{POOIIIIRS \&I PLIITELIRS}

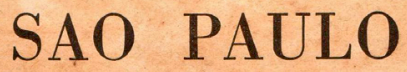
Avec 15 planches hors texte
et 45 figures

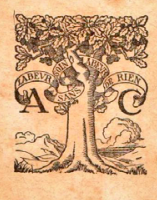

1952

LIBRATRIE ARMAND COLIN

103, boul. Saint-Michel - Paris $\left(5^{\mathrm{e}}\right)$

Tous droits de reproduction, de traduetion et d'adaptation réservés pour tous pays

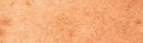

Figura 1. Contracapa da edição de "Pionniers et planteurs de São Paulo", na versão original, em francês. Fonte: Monbeig (1952).

Dividida em três partes, cada uma delas subdividida, por sua vez, em vários capítulos, "Pioneiros e fazendeiros de São Paulo" (1984b) começa com uma análise das condições naturais e históricas, dialogando ativamente com o conhecimento acumulado até então sobre a geografia e a história paulista?. Geologia, clima, relevo e história são apresentados, de forma a caracterizar, com precisão, o espaço onde se dará, nos capítulos seguintes, o estudo da marcha pioneira.

\section{PIERRE MONBEIG}

\section{PIONEIROS E FAZENDEIROS DE SÃO PAULO}

\author{
Tradução: \\ Ary França e Raul de Andrade e Silva
}

$$
\begin{aligned}
& \text { EDITORA HUCITEC } \\
& \text { EDITORA POLIS } \\
& \text { São Paulo, } 1984
\end{aligned}
$$

Figura 2. Contracapa da edição de "Pioneiros e fazendeiros de São Paulo", na versão brasileira, em português. A demora de sua publicação no Brasil não impediu que o livro de Monbeig se tornasse uma referência fundamental nos estudos sobre o estado de São Paulo. Fonte: Monbeig (1984b).

É nesta primeira etapa da obra que se encontra uma argumentação com papel central nas conclusões apresentadas ao longo do livro. Intitulada "A psicologia bandeirante", nela Monbeig (1984a) estabelece um diálogo com as representações dos bandeirantes até então preponderantes na historiografia paulista, que reforçavam a imagem destes como desbravadores do sertão, impulsionados pela ambição e também pela coragem, não deixando de salientar, entretanto, que ao lado dessa

9 Das várias leituras disponíveis sobre a obra "Pioneiros e fazendeiros de São Paulo" (1984b), cito duas em especial: as de Andrade (2011) e de Nogueira (2013).

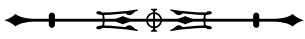


história épica também se encontrava um comportamento marcado pela brutalidade e pela violência ${ }^{10}$. De todo modo, o mito bandeirante parecia ainda animar os fazendeiros e seus feitos. Segundo Monbeig (1984a, p. 212): "Quando se quer celebrar um fazendeiro, desbravador de matas, plantador de cidades, nenhum título melhor a deferir-lhe que o de bandeirante $[\ldots .$.$] .$

Essa imagem exerceu, durante toda a expansão rumo aos sertões paulistas, um papel central, fazendo parte desse conjunto de forças que impulsionavam os colonizadores a seguirem sempre além, em busca de novas terras com potencial agrícola. $\bigcirc$ processo todo é caracterizado por Monbeig (1984b) como uma conquista; e o homem, sujeito dessa marcha, como um verdadeiro invasor" ${ }^{11}$.

O capítulo Il é o que se dedica mais detalhadamente à marcha pioneira, apresentada como um desenvolvimento ainda em decurso pelas terras paulistas, marcado pela velocidade em que se deslocava, mas que, ainda assim, era passível de observação pelo pesquisador. Neste momento, emerge, de forma mais evidente, a excelência do estilo narrativo, com a construção de imagens que remetem o leitor à rapidez dessa sucessão, que se alastrava ferozmente sobre um novo território. Segundo as suas próprias palavras:

Desde que tomou pé nos planaltos ocidentais, prosseguiu a vaga pioneira em sua marcha infatigável, sacudida pelas crises econômicas, acelerada às vezes pelo jogo das circunstâncias políticas mundiais. Incessantemente engrossada por elementos novos, a multidão dos plantadores e dos pioneiros não cessou de progredir, mais ou menos depressa, mas sem fatigar-se. Testemunham avanços sucessivos as cidades, que se sucedem como contas de um rosário, ao longo das ferrovias (Monbeig, 1984b, p. 23).
Pode-se até imaginar o geógrafo observando atentamente a agitação nas estações ferroviárias - pelas quais ele próprio transitava em seus deslocamentos para o interior -, com o rebuliço característico das pessoas em seu vai e vem pelas plataformas, na confusão de sons em meio a mercadorias em transporte. Um local de chegadas e despedidas daqueles que estavam sujeitos tanto aos sonhos de progresso, alimentados pelo mito bandeirante, quanto à desilusão do fracasso, sempre latente, em meio às regiões marcadas por conflitos e violência de toda ordem. Experiências vividas em um cenário onde "[...] tudo é alvoroço, tudo é confusão, tudo é dinamismo [...]" (Monbeig, 1984b, p. 125). Neste capítulo, em especial, o que sobressai são os homens em plena ação, interagindo entre si e com o mundo natural. Além disso, vemos a definição dos meios técnicos e das instituições, construídas para favorecer a expansão e o pleno domínio da natureza. É também o momento da apresentação dos tipos étnicos que se aventuravam nas franjas pioneiras - índios, caboclos, migrantes e imigrantes - e de sua organização social nesse espaço novo e em formação.

A última parte do livro apresenta-nos a zona pioneira na década de 1940, momento final das observações realizadas pelo autor, quando, então, se torna mais evidente a relação de Monbeig com os pressupostos da geografia humana, com a qual ele dialoga tanto quanto contribui, favorecendo a sua consolidação enquanto uma área específica do conhecimento. Sua posição é a de tentar compreender não só os fenômenos na atualidade, mas a atualidade dos fenômenos. Não escapa ao olhar do geógrafo a estrutura fundiária, que ampliava as desigualdades e fortalecia a acumulação capitalista e a

10 mito bandeirante assumiu várias formas e funções, sendo reificado em momentos distintos da história nacional. Especialmente as elites políticas e econômicas paulistas apropriaram-se dos discursos de uma suposta superioridade do povo e da 'raça' paulista desde pelo menos o final do século XIX, utilizando-os como arma simbólica, que buscava garantir distinção aos seus propagadores. Sobre a questão do mito bandeirante, ver Abud (1985), Ferreira (2002) e Ferreira e Mahl (2011).

11 Uma análise específica da representação do bandeirante na obra de Monbeig (1984b) pode ser encontrada em Gonçalves (1998). Neste trabalho, o autor sugere que Monbeig teria efetuado uma leitura liberal daquele momento, que se expressaria, por exemplo, em sua visão "encantada" dos "impulsos individuais" atribuídos aos bandeirantes (Gonçalves, 1998, p. 52), aceitando, portanto, os valores ideológicos reforçados pela chamada historiografia tradicional paulista. 
especulação nas zonas pioneiras, beneficiando as elites formadas pelos grandes proprietários de terra, em prejuízo dos pequenos sitiantes. Surgem também as economias periféricas, tangenciais ao café, e que aos poucos ganham espaço, devido às várias crises econômicas enfrentadas no período. Além disso, Monbeig volta o seu olhar analítico à situação sanitária nas áreas de fronteira, caracterizadas pela precariedade dos modos de vida nos povoamentos, que amplia o sofrimento das populações, principalmente dos mais pobres, ao longo das franjas de ocupação. $\bigcirc$ livro termina com um estudo sobre as cidades surgidas ao longo dessa expansão, sempre atento ao dinamismo desses núcleos, formados geralmente no rastro de fazendas, de cascos e de trilhos, impulsionando as relações sistêmicas entre as zonas de povoamento que se espalhavam pelos novos territórios tomados da floresta.

Essa interpretação sobre a ação pioneira, que se propagava em ondas pelo interior paulista, a partir das últimas décadas do século XIX, produzindo mudanças fundamentais no cenário econômico e social do estado, acabou tornando-se referência fundamental para uma série de estudos de historiadores e de cientistas sociais, extrapolando as fronteiras da geografia. A influência de "Pioneiros e fazendeiros de São Paulo" (1984b), que Novais (2005) define como um estudo modelar, revela-se nos trabalhos sobre a produção algodoeira, de Canabrava (1984); nas pesquisas sobre a demografia e a agricultura paulista de Marcílio (2000); também se vê na obra de Costa (1998), especialmente em "Da senzala à colônia". O historiador Matos (1990) dedica seu consagrado estudo sobre as ferrovias à Pierre Monbeig. Do mesmo modo, a influência do livro também pode ser observada em "Formação econômica do Brasil", de Furtado (1963); e em Candido (2010), no seu "Os parceiros do Rio Bonito". Mais recentemente, o historiador Dean (2000, 1977), autor tanto de estudos sobre a história econômica quanto sobre a história ambiental, também dialoga intensamente com a obra, principalmente em seu trabalho sobre o município de Rio Claro. Esses são alguns exemplos possíveis, entre tantos outros que, em momentos distintos, aproximaram-se das propostas interpretativas do geógrafo francês. Podemos afirmar, portanto, que a obra "Pioneiros e fazendeiros de São Paulo" (1984b) tornou-se, apesar de sua publicação tardia em língua portuguesa, um marco nos estudos sobre a história paulista, compondo, com outros trabalhos, como "Roteiro do café", de Milliet (1946), e "De comunidade a metrópole: biografia de São Paulo", de Morse (1954) - também realizados ao longo das décadas de 1930 e 1940 -, um conjunto que marca ainda hoje a produção intelectual sobre as amplas e complexas transformações impulsionadas pela economia cafeeira.

Entre as diversas possibilidades de leitura que "Pioneiros e fazendeiros de São Paulo" (1984b) oferece ao leitor contemporâneo, uma em especial interessa aos estudiosos da história ambiental, e está voltada para as reflexões sobre as interações entre o homem e o meio ambiente nesse momento de domínio dos sertões de São Paulo. Ao refletir sobre o universo pioneiro, Pierre Monbeig captou, como poucos, tanto os aspectos mais sutis quanto as grandes forças sinérgicas que agiam naquele momento, impulsionando práticas, condutas e ideias. Por fim, a obra oferece um vislumbre dos mecanismos econômicos, políticos, culturais e sociais, os quais contribuíram para a destruição ambiental que se seguiu ao avanço do homem sobre campos e florestas.

\section{O OLHAR DA HISTÓRIA AMBIENTAL}

As décadas de 1960 e 1970 foram fundamentais, segundo os professores McNeill et al. (2010), para a formatação da história ambiental como uma área de pesquisa em construção, mas já com especificidades próprias. Nestas duas décadas iniciais, os historiadores, assim como intelectuais de outras áreas do saber, foram instigados a incorporar as questões ambientais em suas pesquisas, devido principalmente a dois fenômenos. Em primeiro lugar, a maior exposição e a discussão, na esfera pública, dos problemas ambientais relacionados aos impactos das sociedades sobre a natureza, cada vez mais evidentes, e não raro catastróficos; em segundo lugar, o 
desenvolvimento de novas metodologias, principalmente das ciências naturais - e em especial da ecologia -, que passaram a apresentar reflexões inovadoras sobre as relações entre o homem, a sociedade e a natureza ${ }^{12}$. No que se refere especificamente aos historiadores, a inserção da natureza como uma das variáveis a ser considerada para a compreensão dos fenômenos humanos no tempo - além da cultura, da política ou das formas de organização social, por exemplo -, foi o ponto de inflexão que passou a orientar e a dar sentido a um novo caminho, agora percorrido de forma mais precisa e delimitada.

A busca por essa variável ambiental torna-se, entre os historiadores ambientais, que já ocupam espaços destacados com grupos e núcleos de pesquisa consolidados em várias universidades dentro e fora do Brasil, um dos pontos singulares dessa forma de reflexão. Como afirma McNeill (2010), em seu livro "Mosquito empires: ecology and war in the greater Caribbean, 1620-1914", ao justificar a pertinência desse tipo de abordagem, existem momentos da história humana nos quais as relações entre homem e natureza não parecem ser tão importantes e influentes, por exemplo, nos debates intelectuais e teológicos sobre a infalibilidade papal, em meados do século XIX. Entretanto, em outros tempos e lugares, as relações entre história humana e história ecológica são evidentes, e não podem ser desprezadas, a exemplo de quando agentes patológicos específicos, como os causadores da febre amarela e da malária, estudadas pelo autor no contexto do domínio colonial europeu nas Antilhas, parecem influenciar sobremaneira no curso das ações e de decisões, principalmente políticas e militares (McNeill, 2010).

Essa valorização dos fatores ecológicos, nem sempre tão evidentes, abriu aos historiadores novas áreas de exploração. Temos então trabalhos que se dedicaram a refletir sobre a criação de parques, jardins botânicos e unidades de conservação, procurando novos caminhos para uma história política e institucional; enquanto outros buscaram estudar a formação do pensamento ambientalista ao longo do século $X X$, em diálogo com a história cultural, atentos às ideias, aos pensamentos e às representações sociais sobre a natureza. Também se destacam os trabalhos sobre as relações entre o homem e o meio ambiente no tempo, em grande parte analisando os impactos negativos das atividades humanas, determinando as pressões exercidas pelos diferentes sistemas de produção, distribuiçã̃o e consumo, em um claro diálogo com a história econômica. Estes são somente alguns exemplos possíveis, entre tantos outros, que revelam a variedade da produção dos historiadores ambientais na atualidade, os quais trazem, entretanto, como ponto de convergência, segundo afirmação do historiador Pádua (2012, p. 37), o desafio de integrar o "[...] biofísico, o social e o cultural [...]" na história.

Seja qual for a abordagem ou a temática escolhida pelos pesquisadores que se vinculam à chamada história ambiental, é importante ressaltar que ela - da forma como aqui se apresenta - está ligada diretamente ao conhecimento histórico, o qual dispõe de aporte teórico amplo e já bastante consolidado, produzido há tempos no interior da disciplina. Portanto, sendo uma reflexão de historiadores, os sucessos de suas análises dependem, em larga medida, de preparo metodológico adequado, capaz de oferecer ao pesquisador ferramentas que lhe permitam tratar as fontes de forma crítica. Como afirma Prost (2008, p. 54), a história se define como um "[...] conhecimento através de vestígios [...]", e o grande desafio do historiador é conseguir educar o seu olhar para a compreensão, a interpretação e a formulação de hipóteses, agindo, de certo modo, como um verdadeiro investigador ${ }^{13}$. Em relação aos historiadores ambientais, em

\footnotetext{
12 Além da história ambiental, ligada ao campo da história, outros saberes das ciências humanas, como a antropologia, a geografia e a economia, buscaram (re)incorporar o mundo natural em suas pesquisas, por exemplo a antropologia ecológica, a geografia cultural e a ecologia histórica, esta última relacionada diretamente ao materialismo dialético. Sobre as diferenças entre essas abordagens, ver Balée (1998). Para uma reflexão mais específica sobre a leitura marxista das relações entre sociedade e meio ambiente, ver também Martinez (2006).

13 Em relação às similaridades entre o trabalho do historiador e do investigador criminal, ver Ginzburg (1991).
}

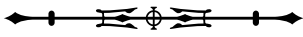


especial, afirma o professor Hughes (2006), em seu livro "What is environmental history?":

Those who describe the historical method (used by all historians) always emphasize the importance of the search for sources of evidence. Among sources, as a rule, the closer to the time, place, and people being studied, the better. By and large, they are talking about written sourcer, in some cases supplemented by oral interviews when that is possible. What could be better than a primary source: for example, an original diary in which a general recorded his thoughts on the eve of a battle? Better, possibly, than a secondary account written later on by someone who had not seen the engagement. Of course an environmental historian will rightly be expected all the written sources that can possibly iluminate the question under investigation. For environmental historians, these sources will include not only all the relevant books and articles, but as the case dictates, business records, scientific reports, newspaper records, and literature revealing the attitudes of people of the times. Websites can be enormously helpful, but are inherently more ephemeral than material published in hard copy; that is, the site may not be there when the researcher tries to access it again, or the desired pages may have been erased ${ }^{14}$ (Hughes, 2006, p. 118-119).

Como se vê, a escolha das fontes de pesquisa é um dos passos decisivos do trabalho do historiador. A partir dela, surge um outro desafio (seja qual for a forma de abordagem): a avaliação crítica desses vestígios, a qual sustentará as explicações e suposições. Para os historiadores ambientais, esta formulação, por vezes bastante complexa, adquire uma singularidade: devido ao seu caráter multidisciplinar, não raro os pesquisadores têm que se apropriar de conhecimentos construídos por outras ciências, como botânica, ecologia ou zoologia, por exemplo. Isso acrescenta um pouco mais de dificuldade, ao exigir esforço do investigador para compreender conceitos de áreas muito distantes da história. Por outro lado, ao voltar a atenção para o mundo natural, os historiadores conseguem recolher traços e significados antes negligenciados em outros estudos. Pode-se, desse modo, afirmar que a história ambiental oferece novas perspectivas sobre as fontes, mesmo sobre aquelas que já foram alvo de análises ligadas a outras vertentes do conhecimento histórico. Isto é resultado desse esforço interpretativo, que passou a considerar o mundo natural, em seus mais amplos e complexos aspectos, como parte das respostas formuladas durante a operação historiográfica.

Portanto, se desde os Annales a história que se procura é a 'história-problema', a natureza pode ser, em determinados momentos, uma das chaves para as tentativas de compreensão e de explicação dos fenômenos que nos cercam. É sob esse olhar, proposto pelos historiadores ambientais, que o trabalho de Pierre Monbeig ganha novos significados, tanto por suas inovadoras perspectivas interpretativas, quanto pelas fontes que ele apresenta e coteja. Isso se observa, por exemplo, no modo como o autor francês analisa as relações entre o homem e o meio ambiente ao longo da obra "Pioneiros e fazendeiros de São Paulo" (1984b).

\section{O LEGADO INTELECTUAL DE "PIONEIROS E FAZENDEIROS DE SÃO PAULO”}

A natureza ocupa um lugar especial em "Pioneiros e fazendeiros de São Paulo" (1984b), uma vez que foi contra

\footnotetext{
14 "Aqueles que descrevem o método histórico (usado por todos os historiadores) sempre enfatizam a importância da procura por fontes de evidência. Dentre as fontes, como uma regra, quanto maior a proximidade no tempo, lugar e pessoas a serem estudadas, melhor. Mas em grande medida, eles estão falando sobre fontes escritas, em muitos casos complementadas por entrevistas orais, quando isto é possível. $\bigcirc$ que poderia ser melhor que uma fonte primária: por exemplo, um diário original em que um General registrou seus pensamentos na véspera de uma batalha? Melhor, possivelmente, que um relato secundário de alguém que não esteve envolvido diretamente nos eventos. É claro que se espera que um historiador ambiental conheça e utilize o método histórico, e colete todas as fontes escritas que possam iluminar a questão sob investigação. Para os historiadores ambientais, estas fontes incluem não somente todos os artigos e livros relevantes, mas também, quando o caso requer, registros de negociações, artigos científicos, reportagens de jornais, e literatura que revele as atitudes das pessoas no tempo. Websites podem ser de grande valia, mas são inerentemente mais efêmeros que textos publicados em suporte material; isto é, o site pode não estar mais disponível quando o pesquisador tentar acessá-lo novamente, ou mesmo a página pode ter sido apagada" (Hughes, 2006, p. 118-119, tradução nossa).
} 
ela que a chamada marcha pioneira se impôs. Resultado de uma atividade econômica febril, a qual despojava a floresta em nome do progresso e do crescimento, a expansão pioneira foi entendida por Monbeig como um movimento amplo e vigoroso, envolvendo a sociedade paulista em uma espécie de faina conquistadora, renovando, de certo modo, o suposto espírito desbravador e aventureiro dos míticos bandeirantes ${ }^{15}$. O alargamento dessas franjas, que seguia em consonância com o esgotamento dos solos e a expansão das vias férreas, trazia em si a essência de uma sociedade recém-gestada, formada por migrantes e imigrantes, ansiosos pela prosperidade material, em busca de terras que assegurassem a pujança sonhada e muitas vezes prometida ${ }^{16}$. Ao lado das fazendas, povoados apareciam imersos em um frenesi econômico, mantendo em plena circulação uma vasta rede de atividades agrícolas e comerciais, que sustentavam o desenvolvimento de dezenas de cidades no interior, desbravado ao som do assovio agudo das locomotivas e do estrondo gerado pelos incêndios que iluminavam os céus noturnos, formando novas áreas de plantio. Essa marcha ruidosa e confusa, a qual incorporou um imenso território à lógica econômica nacional, classificada como "[...] infatigável [...]" por Monbeig (1984b, p. 125), deixou suas marcas avassaladoras sobre a natureza, revelando um lado pouco aprazível do avanço do capital.

Ao longo de toda a obra "Pioneiros e fazendeiros de São Paulo", Monbeig (1984b) mantém o olhar atento para as contradições desse processo econômico, que gerou fortes impactos sobre o ambiente ${ }^{17}$. Segundo o autor, transformações deixaram na paisagem "[...] a marca dessa ofensiva contínua, nos restos de florestas que subsistem, sobre os solos talados por essa cultura devastadora" (Monbeig, 1984b, p. 125). A expressão 'cultura devastadora' merece aqui ser destacada. Monbeig (1984b) não deixa dúvidas quanto ao caráter destrutivo e predatório da produção cafeeira, fundamentada na queimada e no uso dos solos até o seu limite. Suas reflexões são contundentes quanto ao nível de destruição que a produção do café impôs à natureza, prioritariamente aos biomas de florestas. Dessa forma, afirma que "[...] a marcha pioneira fez-se na floresta e contra a floresta $[. .$.$] ", para depois indagar: "Mas, o que$ resta dela hoje?" (Monbeig, 1984b, p. 86). A sua conclusão é contundente. O que restou foi pouco ou quase nada, uma vez que os métodos impediam a renovação do meio natural, devido ao "[...] traumatismo violento que é a queimada [...]" (Monbeig, 1984b, p. 89). A sua perspectiva para o futuro da produção agrícola, após essa ação predatória, passaria agora pela "[...] ação consciente e cientificamente organizada [...]" (Monbeig, 1984b, p. 92), assinalando a necessidade urgente da renovação dos métodos de cultivo, para que a atividade agrícola pudesse se manter após o inevitável esgotamento dos solos e a destruição das florestas, resultante das técnicas comumente empregadas e de difícil abandono, devido, entre outros fatores, ao atraso técnico e educacional encontrado nas zonas pioneiras (Monbeig, 1984b).

Era evidente para Monbeig (1984b) que o meio natural não era mais capaz de sustentar as demandas econômicas e populacionais com o mesmo vigor de outrora, após as

\footnotetext{
15 Ressalta-se aqui, uma vez mais, o intenso diálogo de Monbeig com a historiografia paulista e sua visão 'regionalista' da história. Neste sentido, a revista "Anhembi", de Paulo Duarte, que congregava em seus quadros nomes destacados da intelectualidade paulista, trouxe no mesmo ano de publicação do livro, na França, uma resenha bastante elogiosa, definindo "Pioneiros e fazendeiros de São Paulo" (1984b) como "[...] um verdadeiro monumento à grandeza do Estado de São Paulo" (Pionniers..., 1952, p. 110).

16 A imprensa, em especial, desempenhou papel marcante ao longo das franjas pioneiras, vendendo e propagando os sonhos de riqueza, modernidade, progresso e civilização, na medida em que jornais e revistas iam surgindo, seguindo o ritmo de crescimento das cidades do interior paulista. Sobre essa temática, ver Campos (2009) e Ferreira e Mahl (2008).

17 A expressões 'meio ambiente' e 'ambiente', muito utilizadas nos dias atuais para definir tudo o que pode afetar os organismos vivos, não se destacam no texto de "Pioneiros e fazendeiros de São Paulo". Monbeig (1984b) prefere os substantivos 'florestas', 'plantações' e 'pastagens', além de 'paisagens naturais'. Para compreender o processo de destruição das chamadas 'riquezas naturais', ele geralmente localizava espacialmente uma floresta (oeste, sorocabana, araraquarense), inserindo-a em um relevo (espigões, escarpas), ocupando uma determinada área (planaltos, fundos de vale). Para uma análise do vocabulário ambiental na atualidade, ver Miller Junior (2011).
}

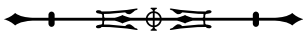


sucessivas marchas pioneiras que seguiram em direção aos planaltos ocidentais paulistas, a partir de 1870, e que se estenderam para além das fronteiras do estado, adentrando o norte do Paraná. As 'terras roxas' já tinham sido exploradas à exaustão, e os arenitos mais frágeis das últimas fronteiras do estado não ofereciam as mesmas facilidades do 'velho oeste'. O que o autor chamou de "[...] invasão dos planaltos ocidentais paulistas [...]" (Monbeig, 1984b, p. 94), primeiramente pelo café e posteriormente pela pecuária, em uma referência a uma batalha que teria sido implementada contra a natureza, havia cobrado um preço alto dos recursos naturais de São Paulo, restando, já na década de 1940, a visão melancólica e bastante saudosista expressada pelos agricultores mais velhos, que recordavam um passado de fausto e grandes facilidades, supostamente vivenciados pelos primeiros desbravadores, e que parecia ter ficado definitivamente para trás (Monbeig, 1984b) (Figura 3).

Ao refletir sobre as contradições do processo de expansão das franjas pioneiras, Monbeig (1984b) realizou a proposta essencial dos novos geógrafos franceses da primeira metade do século $X X$, que faziam uma geografia inserida no tempo, onde diversas camadas de história se entrelaçam e se confundem, atravessadas por diferentes variáveis econômicas, políticas, sociais e culturais. Nesse sentido, o mundo observado por Monbeig (1984b) foi compreendido em sua longa duração: no tempo lento, que se revela gradualmente nas interações entre um meio ambiente natural, descrito de forma minuciosa, bem como nas contradições manifestadas pelos movimentos populacionais, por demandas sociais, por mudanças políticas e por aspectos mentais e simbólicos, marcados sobremaneira pelas variações na economia internacional, na qual o país estava cada vez mais inserido, e à qual ficaria cada vez mais sujeito. Como afirma Roncayolo (2006, p. 127), Pierre Monbeig analisou as transformações do interior paulista pela ótica de uma "[...] geografia em movimento $[\ldots]$ ", percebendo, ao longo desse processo, as “[...] tensões $[\ldots]$ ", as "[...] contradições $[\ldots]$ " e os "[...] esgotamentos $[\ldots]$ ", além dos limites desse modelo de expansão.

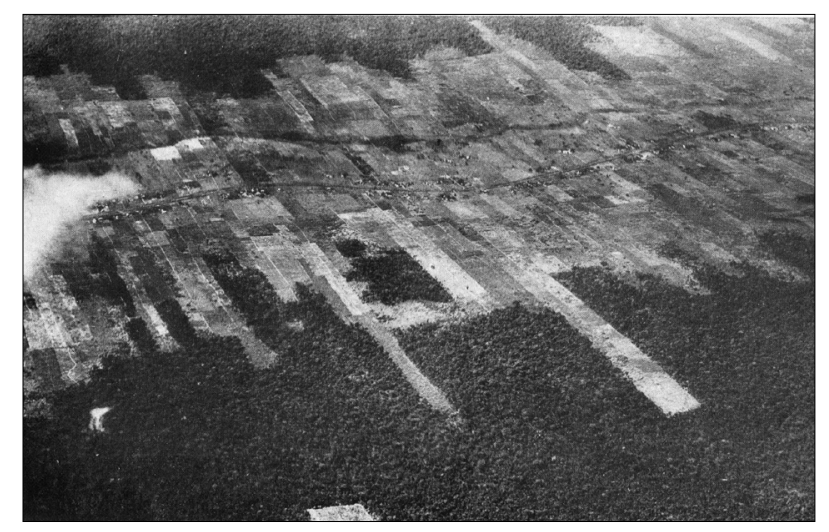

Figura 3. Foto aérea onde se vê o mosaico formado pela abertura de novas áreas de plantio no meio das matas, revelando as manchas de civilização que avançavam pelo território paulista. Fonte: Monbeig (1952).

Para os historiadores ambientais, "Pioneiros e fazendeiros de São Paulo" (1984b) apresenta-se como um texto indispensável aos que desejam estudar as transformações no mundo natural no estado de São Paulo, o que se explica a partir de dois fatores principais. Em primeiro lugar, as interpretações do autor sobre a marcha pioneira compreenderam, naquele momento, o alto preço cobrado da natureza pelos desbravadores. Em outras palavras, o desenvolvimento agrícola do interior paulista, e toda a riqueza e o crescimento material que ela proporcionou, se deu às custas da destruição de grandes e complexos biomas. Nesse sentido, se a armadilha do anacronismo nos impede de definir Pierre Monbeig como um historiador ambiental de primeira hora, não seria errado supor que a sua obra revela uma sensibilidade única para os problemas gerados nas relações entre as sociedades e a natureza, antecipando, portanto, esta questão essencial, a qual instiga muitos dos pesquisadores que, desde a década de 1970, se reconhecem como historiadores ambientais.

Esse tom crítico, parte constitutiva das análises do geógrafo francês e também de muitos de seus colegas do período, vem ao encontro das reflexões elaboradas pelos historiadores ambientais na atualidade, permitindo, assim, um diálogo permanente e fecundo com a obra, mesmo após quase 65 anos de sua publicação em língua francesa.

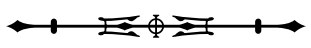


Em segundo lugar, o trabalho de pesquisa feito por Monbeig arrolou um conjunto documental valioso sobre o território paulista e adjacências, principalmente das primeiras décadas do século $X X$. Encontramos no livro tabelas, plantas, diagramas, mapas, indicadores econômicos, dados populacionais, fotografias - muitas realizadas pelo próprio autor -, além de uma bibliografia que remete a trabalhos pouco conhecidos e citados. Fontes de difícil acesso hoje e que estão disponíveis por intermédio dessa pesquisa rigorosa e abrangente. Afinal, quantos arquivos, livros ou bibliotecas precisariam ser visitados para se ter acesso, por exemplo, aos números de cafeicultores, à média de cafeeiros e à produção por plantador nas quatro macrorregiões paulistas (Alta Araraquarense, Noroeste, Alta Paulista, Alta Sorocabana), além do Norte do Paraná, no biênio 1937-1938 (Monbeig, 1984b)? Ou então à distribuição dos imigrantes, por municípios, pioneiros no início da década de 1930 (Monbeig, 1984b)? Essas são informações imprescindíveis para os que estudam as interrelações entre história e meio ambiente. Caminhos abertos por Monbeig, ainda passíveis de exploração ${ }^{18}$.

De certo modo, Pierre Monbeig agiu como um verdadeiro desbravador do interior paulista, compreendendo, como poucos, as contradições e os impasses da experiência pioneira paulista do início do século $X X$. Seria importante que a obra voltasse a circular em uma nova edição, deixando sua inexplicável condição de raridade bibliográfica. Sem dúvida, esta seria uma bela forma de homenagear este francês que tanto se dedicou aos temas e problemas brasileiros.

\section{REFERÊNCIAS}

AB'SÁBER, Aziz. Pierre Monbeig: a herança intelectual de um geógrafo. Estudos Avançados, São Paulo, v. 8, n. 22, p. 221232, quad. 1994. Disponível em: <http://www.scielo.br/pdf/ea/ v8n22/24.pdf>. Acesso em: 25 maio 2016.
ABUD, Kátia Maria. O sangue intimorato e as nobilíssimas tradições: a construção de um símbolo paulista: o bandeirante. 1985. 244 f. Tese (Doutorado em História) - Universidade de São Paulo, São Paulo, 1985.

ANDRADE, Julia Cossermelli de. Pierre Monbeig, um francês diante da geografia do movimento: um estudo sobre a obra Pioneiros e fazendeiros do estado de São Paulo. Revista do Instituto de Estudos Brasileiros, São Paulo, n. 52, p. 43-68, quad. 2011. DOI: < http:// dx.doi.org/10.11606/issn.2316-901X.v0i52p43-68>.

BALÉE, William. Historical ecology: premises and postulates. In: BALÉE, William (Ed.). Advances in historical ecology. New York: Columbia University Press, 1998. p. 13-29.

BRAUDEL, Fernand. USP, 50 anos: lembranças de um pioneiro francês. Revista IstoÉ, São Paulo, n. 371, 1984.

CAMPOS, Raquel Discini de. Mulheres e crianças na imprensa paulista (1920-1940): educação e história. São Paulo: Unesp, 2009.

CANABRAVA, Alice P. O algodão em São Paulo 1861-1875. São Paulo: T. A. Queiroz, 1984.

CANDIDO, Antonio. Os parceiros do Rio Bonito. Rio de Janeiro: Ouro sobre Azul, 2010

COSTA, Emília Viotti da. Da senzala à colônia. São Paulo: Unesp, 1998.

DEAN, Warren. A ferro e fogo: a história e a devastação da Mata Atlântica brasileira. Tradução Cid Knipel Moreira. São Paulo: Companhia das Letras, 2000.

DEAN, Warren. Rio Claro: um sistema brasileiro de grande lavoura (1820-1920). Tradução Waldívia Marchiori Portinho. Rio de Janeiro: Paz e Terra, 1977.

DELACROIX, Christian; DOSSE, François; GARCIA, Patrick. Correntes históricas na França: séculos XIX e XX. Tradução Roberto Ferreira Leal. Rio de Janeiro: FGV, 2012.

FERREIRA, Antonio Celso. A epopéia bandeirante: letrados, instituições, invenção histórica (1870-1940). São Paulo: Unesp, 2002.

FERREIRA, Antonio Celso; MAHL, Marcelo Lapuente. Preservação e patrimônio no Instituto Histórico e Geográfico de São Paulo (18941937). Patrimônio e Memória, São Paulo, v. 7, n. 1, p. 3-18, jun. 2011.

FERREIRA, Antonio Celso; MAHL, Marcelo Lapuente (Org.). Letras e identidades: São Paulo no século XX, capital e interior. São Paulo: Annablume, 2008.

18 A importância das fontes primárias arroladas por Pierre Monbeig em "Pioneiros e fazendeiros de São Paulo" (1984b) também foi apontada pelo resenhista da revista "Anhembi", que afirmou: "Seria um erro julgar que o seu trabalho interessa apenas aos especialistas em geografia. Ele fornece também a mais preciosa documentação ao historiador, ao economista e ao sociólogo" (Pionniers..., 1952, p. 111).

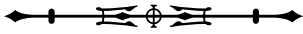


FURTADO, Celso. Formação econômica do Brasil. Brasília: Universidade de Brasília, 1963.

GINZBURG, Carlo. Sinais: raízes de um paradigma indiciário. In: GINZBURG, Carlo (Ed.). Mitos, emblemas, sinais: morfologia e história. Tradução Federico Carotti. São Paulo: Companhia das Letras, 1991. p. 143-179.

GONÇALVES, José Henrique Rollo. Em torno de uma refeitura liberal do mitema bandeirante: Pierre Monbeig e as frentes pioneiras nos anos 30 40. Revista de História Regional, Ponta Grossa, v. 3, n. 1, p. 37-64, inverno 1998.

HUGHES, J. Donald. What is environmental history? Cambridge, UK: Polity Press, 2006.

IUMATTI, Paulo; SEABRA, Manoel; HEIDEMANN, Heinz Dieter (Org.). Caio Prado Junior e a Associação dos Geógrafos Brasileiros. São Paulo: Edusp, 2008.

LÉVI-STRAUSS, Claude. Longe do Brasil. Tradução Jorge Villela. São Paulo: UNESP, 2011.

LÉVI-STRAUSS, Claude; ERIBON, Didier. De perto e de longe. Tradução Léa Mello e Julieta Leite. São Paulo: Cosac Naify, 2005.

MARCÍLIO, Maria Luiza. Crescimento demográfico e evolução agrária paulista (1700-1836). São Paulo: Edusp/Hucitec, 2000

MARTINEZ, Paulo Henrique. História ambiental no Brasil: pesquisa e ensino. São Paulo: Cortez, 2006.

MATOS, Odilon Nogueira de. Café e ferrovias: a evolução ferroviária de São Paulo e o desenvolvimento da cultura cafeeira. Campinas: Pontes, 1990.

MCNEILL, John Robert. Mosquito empires: ecology and war in the greater Caribbean, 1620-1914. New York: Cambridge University Press, 2010.

MCNEILL, John Robert; PÁDUA, José Augusto; RANGARAJAN, Mahesh (Ed.). Environmental history: as if nature existed. New Delhi: Oxford University Press, 2010.

MILLER JUNIOR, G. Tyler. Ciência ambiental. Tradução All Tasks. São Paulo: Cengage Learning, 2011.

MILLIET, Sérgio. Roteiro do café. São Paulo: BIPA, 1946.

MONBEIG, Pierre. O crescimento da cidade de São Paulo. In: Szmrecsányi, Tamás (Org.). História econômica da cidade de São Paulo. São Paulo: Globo, 2004.

MONBEIG, Pierre. A psicologia bandeirante. In: MONBEIG, Pierre. Pioneiros e fazendeiros de São Paulo. Tradução Ary França e Raul de Andrade e Silva. São Paulo: Hucitec/Polis, 1984a. p. 121-127.
MONBEIG, Pierre. Pioneiros e fazendeiros de São Paulo. Tradução Ary França e Raul de Andrade e Silva. São Paulo: Hucitec/Polis, 1984b.

MONBEIG, Pierre. Brasil. São Paulo: Difel, 1969.

MONBEIG, Pierre. Pionniers et planteurs de São Paulo. Paris: Armand Colin, 1952.

MONBEIG, Pierre. Ensaios de geografia humana brasileira. São Paulo: Livraria Martins, 1940.

MORAES, Antonio Carlos Robert. Geografia: pequena história crítica. São Paulo: Hucitec, 1983.

MOREIRA, Ruy. O pensamento geográfico brasileiro. São Paulo: Contexto, 2008

MORSE, Richard M. De comunidade a metrópole: biografia de São Paulo. Tradução Maria Apparecida Madeira Kerbeg. São Paulo: Comissão do IV Centenário da Cidade de São Paulo, 1954.

MOTA, Lourenço Dantas (Org.). A história vivida. São Paulo: $\bigcirc$ Estado de São Paulo, 1981. (Documentos Abertos, v. II).

NOGUEIRA, Carlo Eugênio. O lugar da fronteira na geografia de Pierre Monbeig. 2013. 361 f. Tese (Doutorado em Geografia Humana) - Universidade de São Paulo, São Paulo, 2013.

NOVAIS, Fernando A. Aproximações: estudos de história e historiografia. São Paulo: Cosac Naify, 2005.

PÁDUA, José Augusto. As bases teóricas da história ambiental. In: FRANCO, José Luiz de Andrade; DUTRA E SILVA, Sandro; DRUMMOND, José Augusto; TAVARES, Giovana Galvão (Org.). História ambiental: fronteiras, recursos naturais e conservação da natureza. Rio de Janeiro: Garamond, 2012. p. 17-38.

PIONNIERS et planteurs de São Paulo. Revista Anhembi, São Paulo, ano 2, v. 8, n. 22, p. 108-111, 1952.

PROST, Antoine. Doze lições sobre a história. Tradução Guilherme João de Freitas Teixeira. Belo Horizonte: Autêntica, 2008. (Coleção História e Historiografia).

RONCAYOLO, Marcel. Tempos geográficos e construção dos espaços na análise de Pierre Monbeig. In: SALGUEIRO, Heliana Angotti (Org.). Pierre Monbeig e a geografia humana brasileira: a dinâmica da transformação. Bauru, SP: Edusc, 2006. p. 127.

SALGUEIRO, Heliana Angotti. Introdução. In: SALGUEIRO, Heliana Angotti (Org.). Pierre Monbeig e a geografia humana brasileira: a dinâmica da transformação. Bauru, SP: Edusc, 2006. p. 19. 